\title{
TROPHIC DIFFERENTIATION IN ILYODON, A GENUS OF STREAM-DWELLING GOODEID FISHES: SPECIATION VERSUS ECOLOGICAL POLYMORPHISM
}

\author{
Bruce J. Turner ${ }^{1}$ and Daniel J. Grosse \\ Museum of Zoology, University of Michigan, Ann Arbor, Michigan 48109
}

Received March 15, 1979. Revised September 10, 1979

An impressive diversity of trophic adaptations is a hallmark of teleostean fishes, and has been a characteristic of their evolution that dates from their first appearance in the fossil record. Students of this diversity have usually regarded a particular suite of functionally related trophic specializations as attributes of a given species that adapt it to a particular ecological niche and tend to exclude it from other niches. Generally, though allowance is made for developmental variation or sexual dimorphism, a species has been presumed to have only one set (or a narrow range) of trophic adaptations. It has been thought extremely unlikely for contemporaneous adult members of the same Mendelian population to possess radically different (and mutually exclusive) arrays of trophic features. Thus, especially at or near the species level, ichthyologists have tended to equate trophic differentiation with systematic divergence. The generality of this relationship has recently been seriously challenged. Sage and Selander (1975) have demonstrated that three trophically specialized sympatric cichlids (Cichlasoma) in the Cuatro Ciénagas basin of Coahuila, Mexico, a molluskivore (with molariform pharyngeal teeth and a short gut), an algal detritus feeder (papilliform pharyngeal teeth and a long gut) and a piscivore-all previously thought to be distinct species (Taylor and Minckley, 1966)-exhibited coordinate geographic variation at several allozyme loci, and were therefore most likely conspecific. Vrijenhoek (1978) de-

\footnotetext{
${ }^{1}$ Present address: Department of Biology, Virginia Polytechnic Institute \& State University, Blacksburg, Virginia 24061.
}

tected two trophically divergent, sympatric clones of the triploid unisexual fish species Poeciliopsis 2-monacha-lucida. The clones, though obviously closely related, were differentiated in dental morphology and feeding behavior.

The implications of the discovery of discontinuous trophic polymorphisms in single populations are far-reaching. From the perspective of ichthyology, the existence of such polymorphisms (involving well defined "taxonomic" characters) suggests that the number of biological species involved in several extreme radiations of trophic diversity, most notably those of cichlids in the African Rift lakes (Fryer and Iles, 1972) and of cyprinids in Lake Lanao (Myers, 1960), may have been seriously overestimated by morphological inferences (see also Kornfield, 1978). The nature of the radiations themselves, as well as the systematic utility of trophic characters in general, may have to be reevaluated. From the perspective of ecology, trophic polymorphism implies that "a single species occupies niches that are as distinctly different as is usually the case among validly different species" (Hutchinson, 1978, p. 179), and leads to a host of questions concerning the ecological relationships of the trophic morphs. From the perspective of evolutionary genetics, the discontinous trophic variation may well be the type of niche-specific polymorphism that Maynard Smith (1966) and others have regarded as a fundamental requisite for sympatric speciation.

The only other known case of trophic polymorphism in teleosts is that postulated in species of the characoid genus Saccodon by Roberts (1974): up to four dental morphs occur in what appear to be con- 

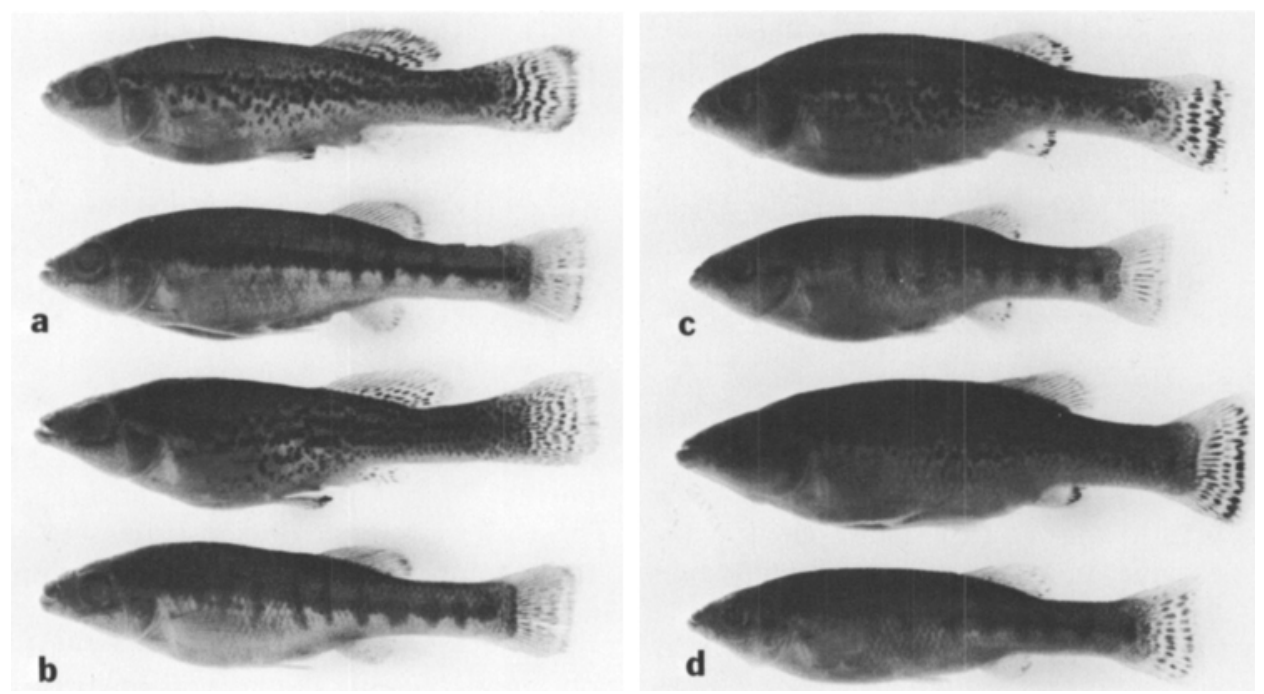

FIG. 1. Lateral views of Ilyodon specimens from "dichotomous" populations, males above, females below, in each. a. Type A, Rio Tuxpan drainage (Rio "Terrero"; UMMZ 191681, male is 56 mm Standard Length). b. Type B, collected simultaneously with "A" (UMMZ 191680, male is $57.5 \mathrm{~mm}$ S.L.). c. Type A, Rio Armeria drainage (Ilyodon furcidens; Rio de Comala; UMMZ 189595, male is $59 \mathrm{~mm}$ S.L.). d. Type B (Ilyodon xantusi); collected simultaneously with "C" (UMMZ 189594, male is $64 \mathrm{~mm} \mathrm{S.L.).}$

specific population samples of these algalgrazing fishes from the mountain streams of Panama and northwestern South America. Unfortunately, genetic or other biological data from the Saccodon dental morphs are entirely lacking.

In this paper we present biochemical genetic analyses of two sets of sympatric, trophically specialized, putative species of a little-known Mexican fish genus, Ilyodon. This genus is a member of the viviparous fish family Goodeidae, a family of less than 40 species of cyprinodontoid fishes with unique reproductive adaptations (Miller and Fitzsimons, 1971). The family is essentially endemic to the Mexican plateau, where it has undergone an adaptive radiation into habitats and trophic niches more usually occupied by members of several other fish families. $I l$ yodon species are small (usually less than $120 \mathrm{~mm}$ total length), laterally compressed, minnow-like fishes (Fig. 1). Unlike nearly all other goodeids (most of which are typically lake dwellers), Ilyodon are fluviatile, like Saccodon, and are almost exclusively confined to the montane rivers that flow off the southwest quad- rant of the Mexican plateau into the $\mathrm{Pa}$ cific Ocean.

The Ilyodon populations of certain tributaries of two river drainages, the Rio Armeria and Rio Tuxpan (=Rio Coahuayana), can be divided into two very distinctive morphological (presumably trophic) "types" (Figs. 2 and 3):

Type "A": The head is tapered, with relatively small jaws; the gape of the mouth is conspicuously lateral, and the jaw teeth (bifid in both types) tend to be short and organized into two obvious rows on the premaxillae (usually one on the dentary bones).

Type "B": The head is very blunt with relatively massive jaws; the gape of the mouth is almost completely transverse (frontal), and the jaw teeth tend to be elongate, posteriorly excavated, fewer in number, and in larger specimens organized in but a single row on both jaws. 

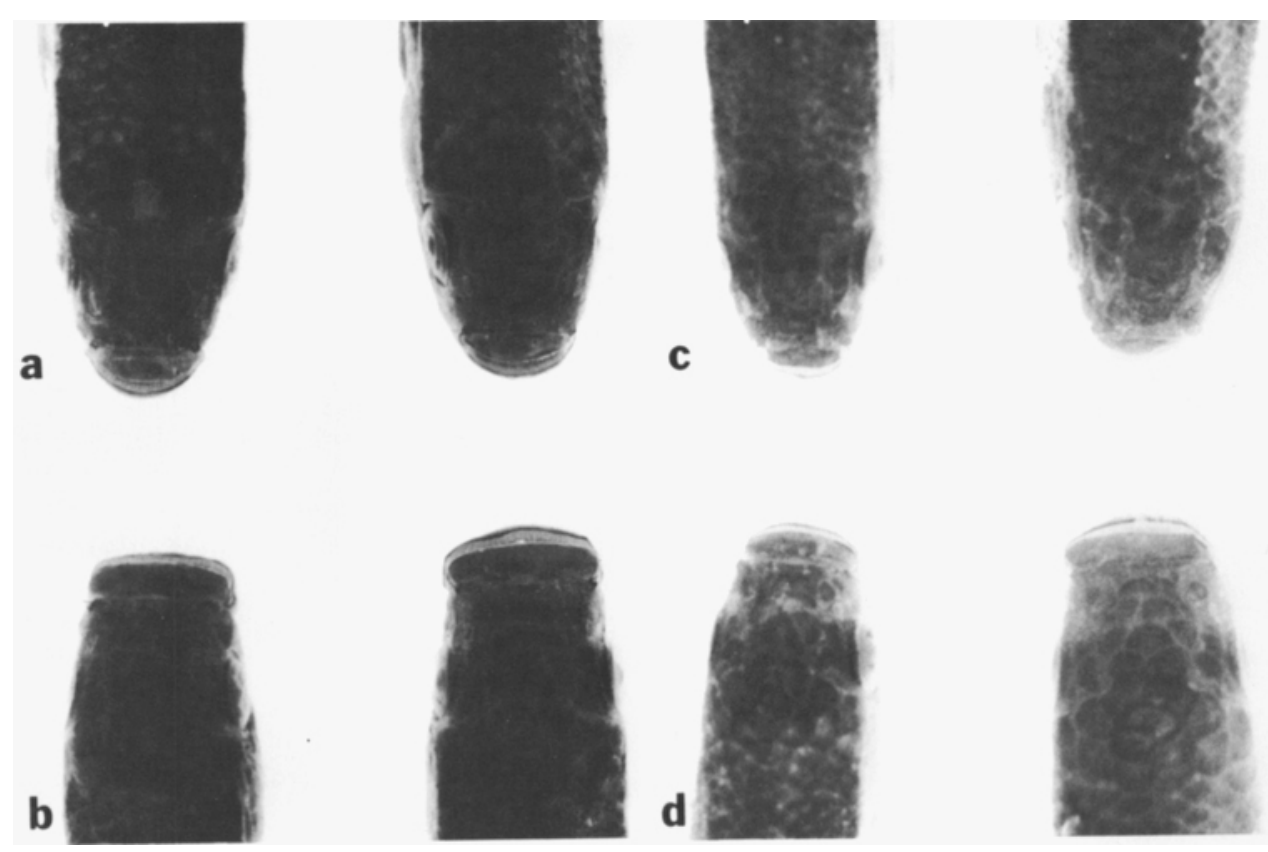

FIG. 2. Enlarged frontal views of specimens shown in Fig. 1; data as in Fig. 1. Note the wider, more massive jaws of the " $B$ " types in both river systems.

The morphology of type "A" suggests that of an insectivore or planktivore, that of "B" a substrate feeder, possibly a harvester of lithophilic algae or small animals; however, no detailed dietary data are yet available. The two trophic types breed true in the laboratory, and develop their distinctive phenotypes when reared on identical diets. They thus probably do not represent "ecophenotypic" or developmental modifications of the same array of genotypes (see discussion by Kornfield and Koehn, 1975). With the exception of a small difference in adult male color pattern in the R. Armeria (see below), the morphological differences between the types are all plausibly associated with divergent trophic adaptations.

The trophic types are quite distinctive, and, if presented with Figure 2 few ichthyologists (ourselves initially included) would hesitate to suggest that they are different species. In the last major taxonomic revision of the family, Hubbs and Turner (1939) recognized the A and B types in the R. Armeria as Ilyodon furcidens and Balsadichthys xantusi, respectively; "Balsadichthys" was vacated in favor of Ilyodon by Miller and Fitzsimons (1971).

The two trophic types are readily differentiated by eye (above a size of about $35 \mathrm{~mm}$ in total length), but relative mouth width (ratio of premaxillary width to head length) provides a convenient discrimination (Hubbs and Turner, 1939). The frequency distribution of the ratio is essentially bimodal in samples of populations that contain both types (Fig. 3).

The two river drainages also contain Ilyodon populations that are not dichotomous, but rather highly variable in trophic features. Those in the R. Tuxpan are otherwise virtually identical to the dichotomous populations. The frequency distributions of the mouth width:head length ratio in these populations are not bimodal (Fig. 3C and D) and means are near the antimode of the dichotomous populations. In the R. Tuxpan drainage, 


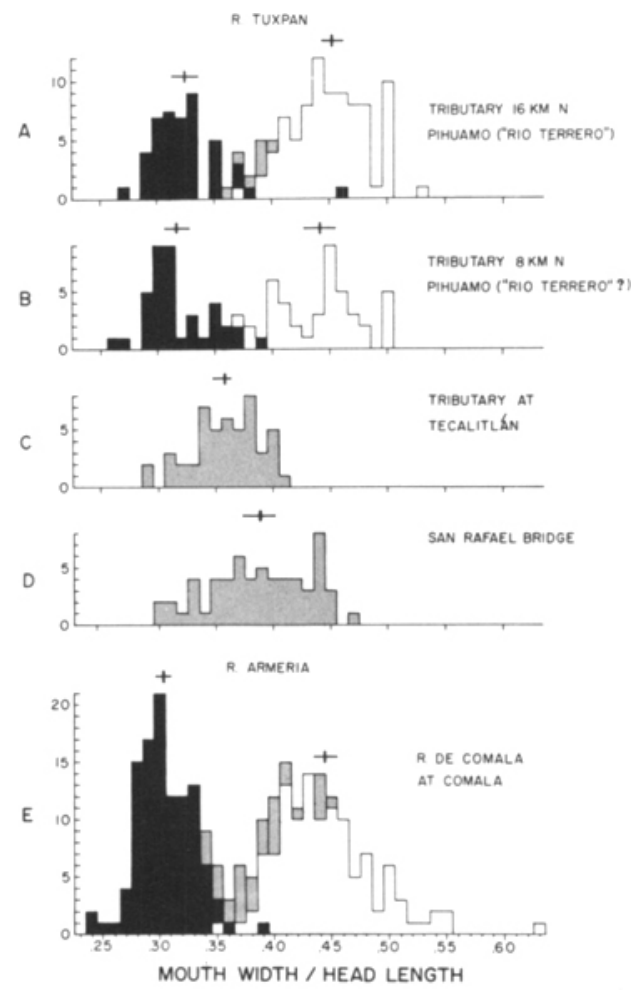

FIG. 3. Histograms of the frequency distributions of relative mouth widths (mouth width/head length) in five Ilyodon samples. Solid black squares represent individuals scored as Type $A$ by eye, open white squares represent those scored as Type B. Striped (gray) boxes represent individuals which could not be reliably scored by eye. Vertical bar above each distribution indicates the position of the mean, horizontal bar the extent of the $99 \%$ confidence interval of the mean (both calculated by the arcsine $[\mathrm{p}]^{1 / 2}$ transformation). A. Allozyme survey sample, Rio Tuxpan, 1977. B. Same or lower tributary, approximately $8 \mathrm{~km}$ downstream from "A"; collected 1955 (UMMZ 172154, 201952). Note similarity of distribution to that of "A." C. Continuous or "nondichotomous" sample; unnamed tributary at Tecalitlan; (UMMZ 189080) preserved material, collected 1968. D. Continuous sample, Rio Tuxpan at San Rafael bridge; preserved material (UMMZ 127160), collected 1975. E. Allozyme survey sample, 1977, Rio de Comala at Comala; Rio Armeria drainage. Unassignable specimens (striped boxes) in "A" and " $E$ " were excluded from the allozyme survey. (See text.)

the unimodal populations appear to be more frequent than the bimodal (dichotomous) ones. It is not known if the two kinds of populations ever occur in the same tributary. The dichotomous popu- lations are encountered almost exclusively in high-gradient tributaries with rock and boulder-strewn substrates and abundant riffles. The non-dichotomous populations are usually found in low-gradient habitats with pebble or silt substrates. When first observed, in collections from the R. Armeria, Ilyodon of intermediate phenotype were regarded as interspecific (and intergeneric) hybrids (Hubbs and Turner, 1939).

Knowledge of the relationships of the trophic types in the dichotomous populations is obviously central to understanding the evolution of trophic diversity in $I l y$ odon. Do they represent discrete gene pools, or are they components of the same Mendelian population? In this paper we attempt to answer this question by comparison of polymorphic allozyme loci in the trophic types in two dichotomous populations, one from each of the river streams. The data suggest that at least one of these sympatric "species pairs" may in fact be a single Mendelian population with discrete trophic morphs.

\section{Materials and Methods}

Specimens.-Samples were taken by poisoning with emulsified rotenone at the following localities:

1. Rio Tuxpan drainage: Rio "Terrero" about $1.5 \mathrm{~km} \mathrm{~W}$ of the town of $21 \mathrm{de}$ Noviembre (16 km by highway $\mathrm{N}$ of Pihuamo), Jalisco, Mexico. September 14, 1977.

2. Rio Armeria drainage: Rio de Comala, just $S$ of the town of Comala, approximately $7 \mathrm{~km} \mathrm{~N}$ of the city of Colima, Mexico. September 13, 1977.

Specimens were frozen on dry ice in the field and held at $-90 \mathrm{C}$ in the laboratory. Assignment of trophic type.-The trophic type of each specimen was determined by eye; specimens that could not be unequivocally assigned to either type were measured but were not analyzed further. Visual discrimination was based on the width and shape of the mouth, features that have a strong allometric relationship with body size. In general, visual discrim- 
ination of the trophic types becomes imprecise below about $35 \mathrm{~mm}$ in standard length, and discrimination even by measurement of relative mouth width becomes virtually impossible below about $25 \mathrm{~mm}$.

Electrophoretic analysis.-The protein products of some 30 presumptive structural genes were surveyed by horizontal starch gel electrophoresis. Details of methods are available upon request.

At each polymorphic locus the genotypic frequency distribution of each of the trophic types in each geographic sample was compared by contingency table (evaluated by Chi-square test of association, or by Fisher's exact method) and the allelic frequencies derived from the genotype data were compared by $t$ test using a method based on arcsine transformations (Sokal and Rohlf, 1969, p. 607). The zygotic frequencies in each of the trophic types were compared to those expected from Hardy-Weinberg equilibrium by Chi-square test, using Yates' correction. Finally, the genotype data from both of the trophic types in each sample were pooled and their distribution compared to a Hardy-Weinberg equilibrium with allelic frequencies derived from the pooled data.

\section{RESULTS}

Determination of trophic types.-The frequency distributions of relative mouth widths in the two samples are shown in Figures $3 \mathrm{~A}$ and $3 \mathrm{E}$; the distributions are clearly bimodal. The two figures also show relative mouth widths for 36 specimens (less than $10 \%$ of the total) that could not be unequivocally assigned to trophic type by eye, and which were excluded from electrophoretic analysis. These specimens do not cluster in the antinodes of the distributions; it is therefore likely that they were not hybrids or intermediates. As a group, they were smaller in size than the rest of the specimens $(\bar{x}=$ $36.8 \pm 1.0 \mathrm{~mm}$ versus $41.9 \pm 0.5 \mathrm{~mm}$ ) and our inability to sort them into categories probably reflects a size-related limitation of our ability to visually discrimi-
TABLE 1. Polymorphic allozyme loci in two allopatric dichotomous Ilyodon populations.

\begin{tabular}{|c|c|c|c|c|}
\hline Locus & Allele & $\begin{array}{c}\begin{array}{c}\text { Relative } \\
\text { mobility } \\
\text { of protein } \\
\times 100\end{array}\end{array}$ & $\begin{array}{c}\text { R. } \\
\text { Tuxpan }\end{array}$ & $\underset{\text { Armeris }}{\mathbf{R} .}$ \\
\hline \multirow[t]{4}{*}{$A d a$} & $a$ & 87 & & + \\
\hline & $b$ & 60 & & + \\
\hline & $c$ & 74 & + & + \\
\hline & $d$ & 100 & & + \\
\hline \multirow[t]{3}{*}{$A g p$} & $a$ & 52 & + & \\
\hline & $b$ & 100 & + & \\
\hline & $c$ & 37 & + & + \\
\hline \multirow[t]{2}{*}{$C p k-1$} & $a$ & 100 & + & + \\
\hline & $b$ & 83 & + & + \\
\hline \multirow[t]{2}{*}{$C_{p k-2}$} & $a$ & 100 & + & + \\
\hline & $b$ & 82 & + & + \\
\hline \multirow[t]{3}{*}{$L d h-3$} & $a$ & 92 & + & + \\
\hline & $b$ & 100 & & + \\
\hline & $c$ & 86 & & + \\
\hline \multirow[t]{2}{*}{$M d h-3$} & $a$ & 100 & + & + \\
\hline & $b$ & 88 & + & \\
\hline \multirow[t]{2}{*}{$P g d$} & $a$ & 89 & + & + \\
\hline & $b$ & 100 & + & \\
\hline \multirow[t]{4}{*}{ Phi-1 } & $a$ & 90 & + & + \\
\hline & $b$ & 100 & & + \\
\hline & $c$ & 75 & & + \\
\hline & $d$ & 78 & & $(+)$ \\
\hline
\end{tabular}

nate between the trophic types; had we sorted by measurement of relative mouth width, nearly every specimen could have been categorized.

General allozyme comparisons.-Five loci were polymorphic (criterion: $p \leqslant .99$ ) in each of the geographic samples (Table 1); but only two, $C p k-1$ and $C p k-2$, were polymorphic in both. Each of the samples contained unique secondary alleles not present in the other. For example, the $A d a$ locus in the Rio Armeria showed a tetra-allelic polymorphism, but was monomorphic in Rio Tuxpan. There were no fixed allelic differences between the $\mathrm{A}$ and $\mathrm{B}$ trophic types in either of the samples.

Heterozygosity. - Comparison of $\bar{H}$, the average proportion of loci heterozygous per individual, are given in Table 2; the table also includes a contingency $\chi^{2}$ comparison of the numbers of individuals heterozygous at zero to four loci in each trophic type. The only significant difference that emerges from these comparisons 
TABLE 2. Heterozygosity and frequency distributions of heterozygous loci ${ }^{1}$ in two dichotomous Ilyodon population samples.

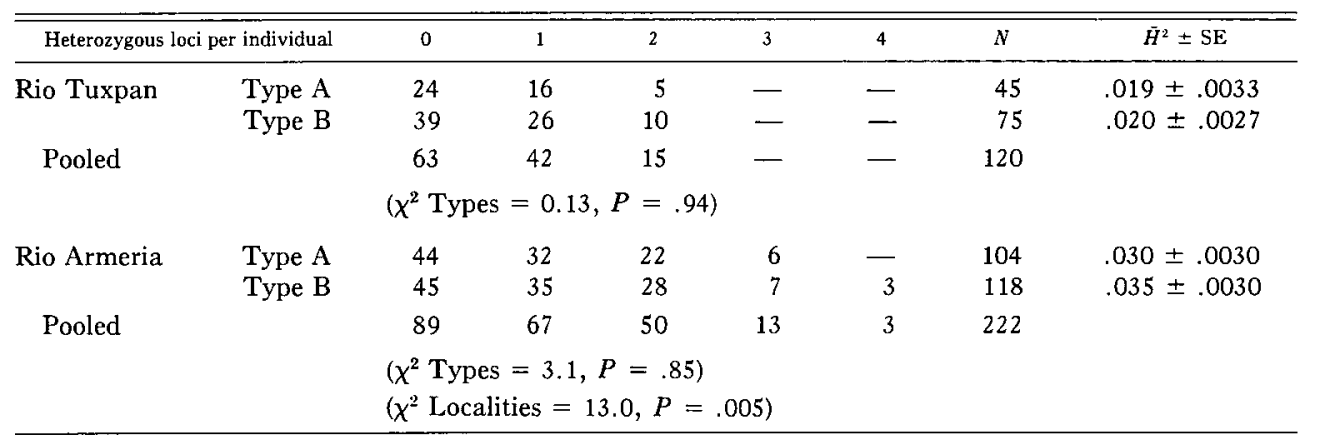

Determined from a survey of 30 loci.

${ }^{2} \bar{H}=$ mean proportion of heterozygous loci per individual.

is between the two pooled geographic samples in the latter comparison. $\vec{H}$ values, in all samples (range .022-.035) are below the average proportional heterozygosity per locus for fishes $(0.0513)$ reported by Nevo (1978).

Comparisons of individual allozyme loci.-In the Rio Tuxpan sample (Table 3), there are no significant differences in genotype or allelic frequencies between types A and B at five polymorphic loci. The contingency probabilities computed for each of the polymorphic loci were used to generate a combined probability test (Sokal and Rohlf, 1969, p. $621 \mathrm{ff}$ ); the resultant probability (Table 3 ) is .47 , well above statistical significance. There is no discernible genetic differentiation between the trophic types. There are no significant departures from zygotic frequencies predicted by Hardy-Weinberg equilibria in either separate or pooled samples. These data offer no support to the hypothesis that the $\mathrm{A}$ and $\mathrm{B}$ trophic types are distinct species, but are consistent with a system of ecological polymorphism involving two trophic "morphs" in a single Mendelian population. However, while they do render it unlikely, for the following reasons the data do not categorically falsify the hypothesis that there is reproductive isolation between the morphs.

The secondary alleles at four of the five polymorphic loci are rare $(q \leqslant .07)$, and the sample size of the " $\mathrm{A}$ " type is small
$(N=45)$. Consequently, the estimates of allelic frequency, especially in the " $\mathrm{A}$ " type, are associated with large standard errors, and small but significant differences may have gone undetected. The importance of this point is enhanced by reports in the literature of rather subtle allozymic differences, some detectable only in pooled data from a number of samples, in several reproductively isolated sympatric sibling fish species (Nyman, 1972; Allendorf et al., 1976; Henricson and Nyman, 1976). Note, however, that if the differences are too subtle, their biological interpretation becomes ambiguous. A small difference in allelic or genotypic frequency at one or a few loci could be interpreted either as evidence of reproductive isolation or of niche-specific selection in a single Mendelian population that is ecologically partitioned (review by Hedrick et al., 1976).

Even if there is absolute identity of allelic frequencies in each of the morphs, interpretation of the data may be confounded by a combination of relatively recent speciation and selection. It is now appreciated that speciation does not necessarily involve major genetic restructuring (Lewontin, 1974, p. 173; other evidence reviewed by White, 1978, p. 43). If the trophic types are reproductively isolated descendants of an immediate common ancestor, and the loci in question were polymorphic in the ancestral popu- 
TABLE 3. Genotype and allelic frequencies at polymorphic allozyme loci in a dichotomous Ilyodon population from the $R$. Tuxpan drainage (" $R$. Terrero").

\begin{tabular}{|c|c|c|c|c|c|c|c|c|c|c|c|c|c|c|c|c|}
\hline \multirow[b]{3}{*}{ Locus } & \multirow[b]{3}{*}{ Morph } & & & & & \multirow[b]{3}{*}{$N$} & \multirow{2}{*}{\multicolumn{3}{|c|}{ Association }} & \multirow{2}{*}{\multicolumn{3}{|c|}{ Allele frequencies }} & \multicolumn{4}{|c|}{ Hardy-Weinberg } \\
\hline & & \multicolumn{4}{|c|}{ Presumptive genotypes } & & & & & & & & Sep & rate & & \\
\hline & & $a / a$ & $a / b$ & $b / b$ & $a / c$ & & $x^{2}$ & $d . f$. & $P$ & $p$ & $q$ & $r$ & $x^{2}$ & $P$ & $x^{2}$ & $P$ \\
\hline \multirow{3}{*}{$A g p$} & A & 24 & 18 & 2 & 1 & 45 & \multirow{3}{*}{1.6} & \multirow{3}{*}{2} & \multirow{3}{*}{0.63} & .74 & .24 & .02 & .7 & .87 & \multirow{3}{*}{1.2} & \multirow{3}{*}{.76} \\
\hline & & & & & & & & & & & & & & & & \\
\hline & $\mathrm{B}$ & 45 & 21 & 4 & 3 & 73 & & & & .78 & .20 & .02 & 1.4 & .72 & & \\
\hline \multirow{3}{*}{$C p k-2$} & A & 43 & 2 & - & - & 45 & \multirow{3}{*}{$(F)^{1}$} & \multirow{3}{*}{-} & \multirow{3}{*}{0.69} & .98 & .02 & - & .02 & .90 & \multirow{3}{*}{.17} & \multirow{3}{*}{.76} \\
\hline & & & & & & & & & & & & & & & & \\
\hline & B & 78 & 7 & - & - & 85 & & & & .96 & .04 & 一 & .16 & .77 & & \\
\hline \multirow{3}{*}{$C p k-3$} & A & 44 & 1 & - & - & 45 & \multirow{3}{*}{$(F)$} & \multirow{3}{*}{-} & \multirow{3}{*}{0.15} & .99 & .01 & - & .02 & .90 & \multirow{3}{*}{.20} & \multirow{3}{*}{.73} \\
\hline & & & & & & & & & & & & & & & & \\
\hline & B & 74 & 9 & - & - & 83 & & & & .95 & .05 & - & .03 & .66 & & \\
\hline \multirow[b]{2}{*}{$M d h-3$} & A & 39 & 6 & - & - & 45 & \multirow[b]{2}{*}{$(F)$} & \multirow[b]{2}{*}{-} & \multirow[b]{2}{*}{0.16} & .93 & .07 & - & .23 & .71 & \multirow[b]{2}{*}{.21} & \multirow[b]{2}{*}{.72} \\
\hline & B & 81 & 4 & - & - & 85 & & & & .98 & .02 & - & .05 & .87 & & \\
\hline \multirow{3}{*}{$P g d$} & A & 41 & 3 & 1 & - & 45 & & & & .94 & .06 & - & 1.2 & .37 & & \\
\hline & & & & & & & .009 & 1 & 0.93 & & & & & & .15 & .78 \\
\hline & B & 77 & 8 & - & - & 85 & & & & .95 & .05 & - & .2 & .73 & & \\
\hline
\end{tabular}

Fisher's combined probability test ${ }^{2}:-2 \sum_{i=1}^{N} \ln P_{i}=9.9$, d.f. $=10$

1 " $F "=$ Prob. calculated by Fisher's exact method.

${ }^{2}$ Sokal \& Rohif $(1969$, p. 621$)$.

lation, speciation might have occured without allelic substitution or fixation. The alleles at all five loci would then persist in the two descendant gene pools. There is evidence that the fitness of some allozymic variants is correlated with physical environmental variables, especially temperature (Mitton and Koehn, 1975; other literature reviewed by Nevo, 1978, p. 163). If all alleles were present in both descendant gene pools, and temperature or some other physical property of the environment were the main determinant of the allelic frequencies at the polymorphic loci, then identity of allelic frequencies in the two morphs would be simply a function of their existence in the same habitat. This explanation of allelic identity involves a combination of events of low probability: speciation without substitution or fixation of least one of the loci and determination of allelic frequencies at all five of them by physical ecological variables. The sequence is therefore unlikely, but it is a possibility that we have not excluded.
The argument that allelic frequency identity implies conspecificity assumes that the alleles at any locus in each of the morphs are truly identical. Allelic identity, as opposed to electrophoretic equivalence, has not yet been established in $\mathrm{Il}$ yodon. Electrophoretic equivalence may be misleading: the work of Johnson (1977) and Coyne (1976) suggests that seemingly identical allozymes may well be differentiated by additional techniques. If "step models" (Cobbs and Prakash, 1977) of electrophoretic variation in natural populations have broad applicability, then this consideration becomes especially pertinent to any hypothesis of conspecificity based on allozyme data, for these models imply that electrophoretic equivalence of nonidentical proteins may be quite common. The allozymes of Ilyodon have thus far been characterized only in routine survey systems of moderate resolving power.

Thus, conspecificity of the trophic types is the simplest explanation of their allozymic identity, and the one supported by the vast bulk of the data on the allozymic 


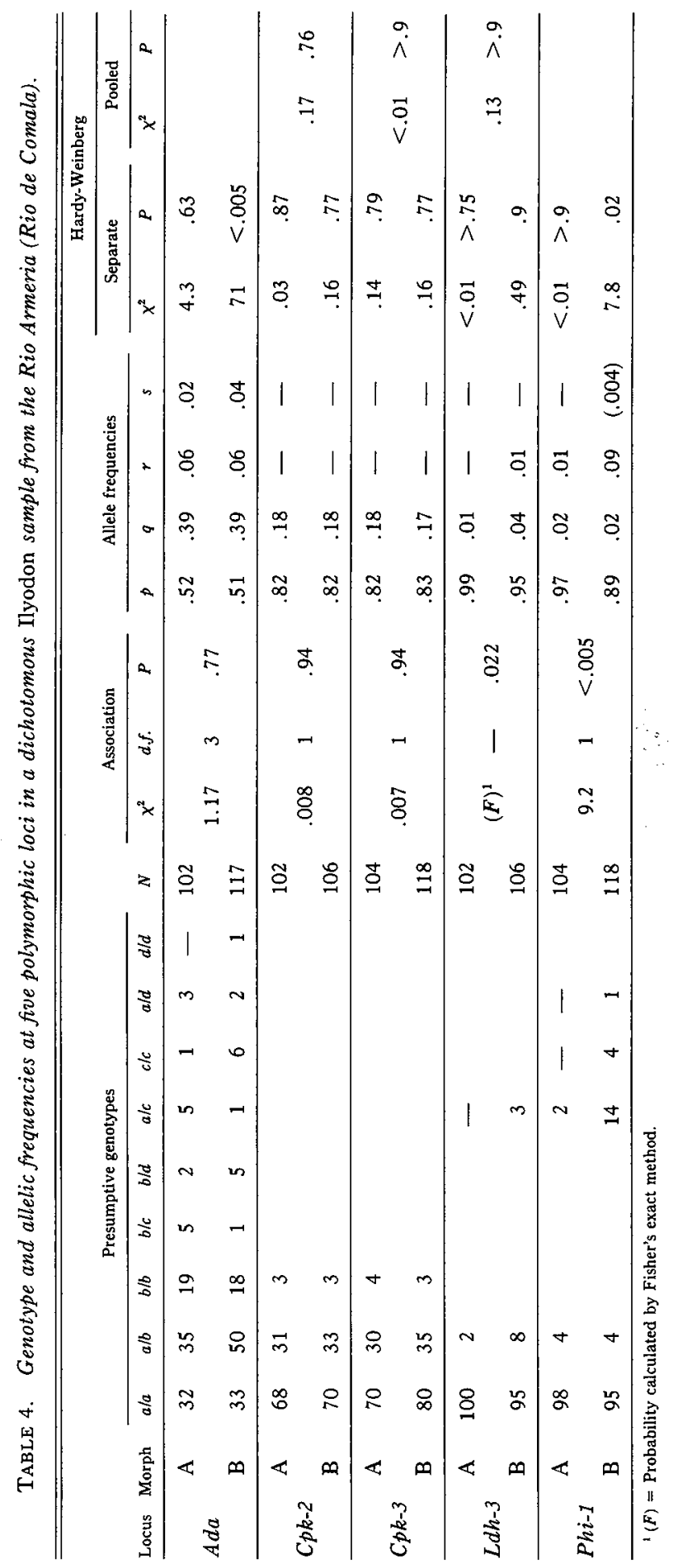


differentiation of species (Avise, 1974, 1976; Ayala, 1975), but the possibility that they are reproductively isolated has not been entirely eliminated.

In the Rio Armeria sample (Table 4), there are statistically significant differences between the genotype frequency distributions of the two trophic types at two loci, Ldh-3 $(P=.022)$ and $P h i-1 \quad(P<$ $.005)$. There is also a significant difference in allelic frequency at the $P h i-1$ locus $\left(p_{A}=\right.$ $\left..97, p_{B}=.89, t=2.44, .02>P>.01\right)$. There are, in the " $B$ " trophic type only, significant departures from the zygotic frequencies predicted by Hardy-Weinberg equilibria at two loci: $\operatorname{Ada}(P<.005)$ and Phi-1 $(P=.02)$. At the $A d a$ locus, $86.3 \%$ of the Chi-square value is due to an excess of $P h i-c$ homozygotes. At the $P h i-1$ locus, $86.2 \%$ of the Chi-square value is due to an excess of $P h i-1 c$ homozygotes, and $13.1 \%$ to a deficiency of " $a / c$ " heterozygotes. At present we have no ready explanation for the excess of homozygotes at the two loci in the B morph. Among the potential causes are selection against certain heterozygotes, the presence of a null allele at one or both loci, inbreeding, or Wahlund effects. Of these, inbreeding appears intrinsically unlikely in large populations of goodeids, and can probably be eliminated. Since the heterozygote deficiency occurs at two loci, a Wahlund effect (produced by subdivision of the sample of the $B$ morph with respect to the " $c$ " allele at both loci appears to be the most parsimonious explanation, but we lack data to exclude other factors. Overall, the allozyme data are consistent with the hypothesis that there is reproductive isolation between the trophic types in this geographic sample. However, the virtual allelic identity of the morphs at four of the five polymorphic loci, and the definite possibility that the " $B$ " type itself may be genetically subdivided, suggest caution in the interpretation of the data: a portion of the population with a " $B$ " trophic phenotype might not be reproductively isolated from the "A" type. Further work may demonstrate that genetic differentiation or reproductive iso- lation of the trophic types in the Rio Armeria is a function of locality, cohort, microhabitat, or some other ecological variable.

A difference in fin colors (first noted by Hubbs and Turner, 1939) may facilitate whatever level of reproductive isolation exists in the Rio Armeria Ilyodon. In a large fraction of males of the " $B$ " type, yellow pigment in the dorsal and/or caudal fins is concentrated into well defined, relatively intense, terminal or subterminal bands. In the "A" morph, the yellow pigment, when present at all, is invariably diffuse and of reduced intensity. This difference in color pattern could serve as a visual cue in a behavioral isolating mechanism involved in assortative mating. If this is the case, variability of the bands within the "B" morph may be of significance. In our sample, about $70 \%$ of the males in the " $\mathrm{B}$ " morph had conspicious yellow bands on one or both fins, but roughly $30 \%$ lacked the yellow bands entirely; the mean sizes of the two kinds of males ("yellow" and "not yellow") could not be statistically distinguished.

\section{DISCUSSION}

The simplest interpretation of the allozyme data from the Rio Tuxpan (Rio "Terrero") sample is that the two types (morphs) are conspecific and are components of a trophic polymorphism segregating within a single Mendelian population. In the Rio Armeria (Rio de Comala) sample, reproductive isolation, or at least some genetic differentiation, probably exists between the " $A$ " trophic type and at least a portion of the " $B$ " type, but the overall genic similarity of the types is nonetheless most impressive, and may well indicate that their separation was very recent.

The hypothesis of conspecificity of the two trophic types in the Rio Tuxpan, strongly suggested but not proven by our analysis, is likely to be somewhat controversial. Conspecificity cannot be excluded by the demonstration of additional morphological differences between the types. Unless the number of newly-discovered 
divergent characters is very large, the differences could theoretically be attributed to pleiotropy of the genes encoding the trophic features themselves, or to adaptively mediated linkages with those genes. The level of reproductive isolation of the types should be assessed directly, and preferably by a variety of biological criteria.

If the trophic types in the Rio Tuxpan are not conspecific, their reproductive isolation may have evolved by sympatric speciation involving allelic substitutions at but a few critical loci (sensu Tauber and Tauber, 1977a, 1977b); their apparent allozymic identity and absolute sympatry appears much more difficult to explain by orthodox geographical or quantum speciation (e.g., Dobzhansky et al., 1977). The trophic types in the Rio Armeria are probably reproductively isolated, but their great overall genic similarity again suggests that their speciation involved minimal allelic substitution, and may well have occurred in sympatry.

The following is a crude model for the evolution of trophic diversity in Ilyodon. It is suggested by the great genic similarity of the sharply distinct trophic types in dichotomous (bimodal) populations in both the Rio Tuxpan and Rio Armeria, the virtual restriction of these populations to certain characteristic habitats, and the existence of "intermediates" (continuous populations) in other habitats. (1.) The continuous populations are not interspecific hybrids, but are simply trophically variable Ilyodon populations adapted to low-gradient streams with mud, silt or pebble substrates and with few large rocks or boulders. (2.) In high-gradient tributaries with large boulders, disruptive selection has favored genes encoding extreme trophic phenotypes. (The original Ilyodon colonists of these streams were probably of intermediate phenotype.) The environmental basis of the hypothetical disruptive selection are at present unknown, but such habitats may have provided some new food sources (e.g., algae or other organisms attached to the surfaces of large rocks) and eliminated others (e.g., spe- cialized microfauna associated with silt substrates). The selection was almost certainly in the direction of increasing trophic specialization. The trophic phenotypes favored by selection were extremes of relative mouth (jaw) width, jaw development, and tooth morphology, number and placement. Precise combinations of extreme features were involved. (There may have been some favorable associations even in the original continuous population.) (3.) Since genotypes encoding intermediate phenotypes or the "wrong" combination of extreme trophic features were of reduced fitness, selection favored the evolution of a polymorphic "system," consisting of alternative arrays of specific (and mutally exclusive) trophic adaptations. These polymorphic systems are probably under the genetic control of "supergenes" (sensu Ford, 1975); each supergene might consist of a single, highly pleiotropic "principal" locus and modifiers controlling dominance, or of several major loci separately encoding jaw development, tooth number, etc. (4.) In some dichotomous populations the trophic types may have acquired reproductive isolation, in sympatry, via mechanisms similar to those discussed in detail by Tauber and Tauber $(1977 a)$. It is not clear whether the acquisition of reproductive isolation is a necessary consequence of the evolution of trophic specialization of Ilyodon, or if it is simply an alternative (one perhaps initially fostered by selection favoring assortative mating) to a highly developed polymorphic system. A central component of the model is the hypothesis that trophic polymorphisms in Ilyodon populations are encoded by supergenes essentially analogous to those controlling pigment and pattern polymorphisms in certain mimetic lepidopterans. If more than one locus is involved in determining the trophic phenotypes (and this is very likely the case), this hypothesis is certainly plausible (see discussions by Ford, 1975; and Turner, 1967a, 1967b). Its evaluation however, will require vastly increased knowledge of the genetics underlying the trophic features of both the dichotomous and the 
continuous populations, and may prove difficult. Our model does predict that dichotomous Ilyodon populations should exist in other high-gradient, rock-laden tributaries of both rivers, tributaries not directly connected to the Rio Terrero or Rio de Comala; in addition, they may also be encountered in equivalent habitats in other river systems where Ilyodon occur (notably the Rio Balsas). In all such new cases, the trophic types should be extremely similar genetically (whether or not reproductive isolation has evolved) and should be more closely related to nearby continuous populations than to more distant discontinuous ones.

Polymorphism involving alternative suites of functionally interrelated morphological specializations has now been implicated in the trophic adaptations of members of three highly divergent groups of teleosts: Cichlasoma (Cichlidae, order Perciformes), Saccodon (Parodontidae, order Cypriniformes) and Ilyodon (Goodeidae, order Atheriniformes). This wide taxonomic distribution strongly suggests that the phenomenon may be a more significant feature of teleost evolution than has been previously appreciated, and may well have been overlooked in many groups.

\section{SUMMARY}

Certain populations of the fluviatile Mexican fish genus Ilyodon (family Goodeidae), in a few tributaries of two adjacent river systems, are sharply dichotomous with respect to suites of trophic specializations. These trophic types have been considered specifically distinct; they are easily differentiated, by eye, as adults and breed true in the laboratory. Nondichotomous populations are found in other tributaries of the same rivers. In a sample from the Rio Terrero, a tributary of the R. Tuxpan (R. Coahuayana), five of 30 allozyme loci surveyed were identically polymorphic in both trophic types. All genotype (zygotic) frequencies were in agreement with those predicted by HardyWeinberg equilibria, and agreement was maintained when the data from the two types were pooled. Conspecificity of the trophic types appears to be the most straightforward interpretation of the data: the sharp trophic differences are probably a discontinuous polymorphism segregating within a local population of a single biological species. The relationships of the trophic types in a sample from the Rio de Comala seem more complex. Of five loci polymorphic in both types, significant differences between the types were detected in the allelic frequencies of one locus and in the genotypic frequencies of a second. In one of the types, highly significant heterozygote deficiencies were detected at two loci. A Wahlund effect (subdivision with respect to genotype frequencies at both loci) is suggested as the best explanation for simultaneous deficiencies at two loci. Thus, there is a possibility that one of the types consists of two or more genetically distinct populations. Dichotomous Ilyodon populations may have evolved from continuous ones in special habitats by disruptive selection favoring extreme trophic phenotypes, followed by the establishment of clear-cut polymorphisms probably encoded by supergenes. The final step in the process may be the acquisition by the trophic types of reproductive isolation in sympatry.

\section{ACKNOWLEDGMENTS}

We thank R. R. Miller for suggesting that a genetic comparison of the Ilyodon trophic types might be of interest, and for placing his extensive personal knowledge and collections of the genus at our disposal. Dr. Miller collected and studied $l l y$ odon populations in the Rio Tuxpan drainage as early as 1955, and our work would have been quite impossible without his pioneering efforts. Thanks are also extended to Ms. D. Kingston, now engaged in a taxonomic revision of the genus; though she does not endorse our conclusions, Ms. Kingston repeatedly facilitated our studies in the best traditions of professional science. We thank B. L. H. Brett, B. Chernoff, J. Humphries, and P. Yant for helpful discussions, and M. L. Smith and Jayantha Wijeyaratne for expert as- 
sistance in the field and laboratory, respectively. The manuscript profited from editorial suggestions of R. M. Andrews, T. A. Jenssen and J. A. Cranford.

The cooperation of the Mexican government, through a collecting permit issued by Lic. Alfonso Yanez Ramos, Director General de Regiones Pesqueras, Instituto Nacional de Pesca, is gratefully acknowledged. Supported by NSF grants DEB 7620958 (BJT) and DEB 77-17515 (R. R. Miller).

\section{LiteratuRe Cited}

Allendorf, F., N. Ryman, A. Stennek, and G. STAHL. 1976. Genetic variation in Scandinavian brown trout (Salmo trutta L.): evidence of distinct sympatric populations. Hereditas 83:7382.

Avise, J. 1974. Systematic value of electrophoretic data. Syst. Zool. 23:465-481.

. 1976. Genetic differentiation during speciation, p. 106-122. In F. J. Ayala (ed.), Molecular Evolution. Sinauer, Sunderland.

Ayala, F. J. 1975. Genetic differentiation during the speciation process. Evol. Biol. 8:1-78.

Cobbs, G., and S. Prakash. 1977. An experimental investigation of the unit charge model of protein polymorphism and its relation to the esterase-5 locus of Drosophila pseudoobscura, $D$. persimilis and $D$. miranda. Genetics 87:712-742.

COYNE, J. 1976. Lack of genic similarity between two sibling species of Drosophila as revealed by varied techniques. Genetics 84:593-607.

Dobzhansky, Th., F. J. Ayala, C. L. Stebbins, AND J. W. Valentine. 1977. Evolution. W. H. Freeman and Co., San Francisco.

Fryer, G., AND T. D. Iles. 1972. The Cichlid Fishes of the Great Lakes of Africa. Oliver and Boyd, Edinburgh.

ForD, E. B. 1975. Ecological Genetics. 4th Ed. Halstead Press, John Wiley and Sons, N.Y.

Hedrick, P. W., M. E. Ginevan, and E. P. EwING. 1976. Genetic polymorphism in heterogeneous environments. Ann. Rev. Ecol. Syst. 7:132.

Henricson, J., and L. Nyman. 1976. The ecological and genetical segregation of two sympatric species of dwarfed char (Salvelinus alpinus (L.) species complex). Rep. Inst. Freshw. Res. Drottningholm No. 55:15-37.

Hubbs, C. L., and C. L. Turner. 1939. Studies of the fishes of the order Cyprinodontes. XVI. A revision of the Goodeidae. Misc. Publ. Mus. Zool. Univ. Michigan No. 42: 5-80, plates I-V.

Hutchinson, G. E. 1978. An Introduction to Population Ecology. Yale Univ. Press, New Haven.
Johnson, G. B. 1977. Assessing electrophoretic similarity. Ann. Rev. Ecol. Syst. 8:309-328.

KoRNFIELD, I. L. 1978. Evidence for rapid speciation in African cichlid fishes. Experientia 34:335336.

KORNFIELD, I. L., AND R. K. KOEHN. 1975. Genetic variation and speciation in New World cichlids. Evolution 29:427-437.

Lewontin, R. C. 1974. The Genetic Basis of Evolutionary Change. Columbia Univ. Press, N.Y.

MAYNARD SMITH, J. 1966. Sympatric speciation. Amer. Natur. 100:637-650.

Miller, R. R., AND J. M. Fitzsimons. 1971. Ameca splendens, a new genus and species of goodeid fish from western Mexico, with remarks on the classification of the Goodeidae. Copeia 1971:1-13.

Mitton, J. B., And R. K. Koenn. 1975. Genetic organization and adaptive response of allozymes to ecological variables in Fundulus heteroclitus. Genetics 79:97-111.

Myers, G. S. 1960. The endemic fish fauna of Lake Lanao, and the evolution of higher taxonomic categories. Evolution 14:323-333.

Nevo, E. 1978. Genetic variation in natural populations: patterns and theory. Theoret. Pop. Biol. 13:121-177.

Nyman, L. 1972. A new approach to the taxonomy of the "Salvelinus alpinus species complex." Rep. Inst. Freshw. Res. Drottningholm No. 52:103131.

RoBerTs, T. R. 1974. Dental polymorphism and systematics in Saccodon, a neotropical genus of freshwater fishes (Parodontidae, Characoidei). J. Zool. (London) 1973:303-321.

Sage, R. D., and R. K. Selander. 1975. Trophic radiation through polymorphism in cichlid fishes. Proc. Nat. Acad. Sci. USA 72:4669-4673.

SoKal, R. R., AND F. J. RoHLF. 1969. Biometry. W. H. Freeman and Co., San Francisco.

TAuber, C. A., AND M. J. TAuber. 1977a. A genetic model for sympatric speciation through habitat diversification and seasonal isolation. Nature 268:702-705.

- 1977b. Sympatric speciation based on allelic changes at three loci: evidence from natural populations in two habitats. Science 197:12981299.

TAylor, D. W., AND W. L. Minckley. 1966. New world for biologists. Pacific Discovery 19:18-22.

TURner, J. R. G. 1967a. The evolution of supergenes. Amer. Natur. 101:195-221.

1967b. Why does the genotype not congeal? Evolution 21:645-656.

VRIJENhOEK, R. C. 1978. Coexistence of clones in a heterogeneous environment. Science 199:549552.

White, M. J. D. 1978. Modes of Speciation. W. H. Freeman and Co., San Francisco.

Corresponding Editor: J. R. Powell 